\title{
TERMINOLOGY, DIFFERENCES, AND CHALLENGES OF COMMUNICATIONS-BASED TRAIN CONTROL AND EUROPEAN TRAIN CONTROL SYSTEMS
}

\author{
LAURA MARTINEZ \& ULLRICH MARTIN \\ Institute of Railway and Transportation Engineering (IEV), University of Stuttgart, Germany
}

\begin{abstract}
Control systems guarantee safe train operations by (1) monitoring and supervising train speed, (2) defining the next allowable target position, and (3) activating automatic braking systems. Two different train control systems, (1) Communications-Based Train Control (CBTC) and (2) European Train Control Systems (ETCS), are usually implemented for railway operations. Among those systems, the CBTC is applied for light railway and urban mass-transit systems, whereas ETCS is used for heavy railway systems. These two train control systems have been used worldwide for more than 20 years. Although both systems share a common field of application, their scope, functionalities, and automation aims differ. This paper reviews the CBTC and ETCS systems, and their underlying moving principles. The applicability, terminology, differences, and challenges with regard to levels of implementation, radio communication systems, train integrity, and interoperability are analysed in detail. Based on this analysis, potential characteristics are identified that could be adopted from these systems to improve railway operation.

Keywords: Fixed Block, Moving Block, Communications-Based Train Control (CBTC), European Train Control Systems (ETCS), Train Control, Automatic Train Operation (ATO), Automatic Train Protection (ATP), Automatic Train Supervision (ATS).
\end{abstract}

\section{INTRODUCTION}

Communications-Based Train Control (CBTC) and European Train Control System (ETCS) are recognised in the railway sector - as their names suggest - as train control systems; however, ETCS sometimes is also referred as a train protection system. Despite their apparent similarity, their development and application areas have gone different ways.

ETCS was designed as an interoperable and fail-safe solution (i.e. in case of equipment or software failure, it will not endanger lives or property) initially just for European Union (EU) countries to supervise train movement depending on the speed limit. However, its popularity is far-reaching, especially in continents such as Asia and Africa [1]. To achieve the goal of interoperability, many EU stakeholders were involved in the development of specifications and further implementation, this degree of complexity slowed down the specification process. Currently, ERTMS has defined three ETCS levels: Level 1 and Level 2 have already been implemented and are detailed in the main versions of the system requirement specification, and the Level 3 specifications are currently under development (Section 4.1). Level 1 and Level 2 operate under the logic of Fixed Block Operation, while Level 3 under the logic of Moving Block Operation. These two separation principles are covered in the next section.

CBTC systems operate under the logic of the moving block separation principle. It has the following main characteristics: (1) precise train position determination at any given time independent of using track circuits or axle counters; (2) continuous track-to-train communication; and (3) an implementation of functions related to safe train operation as well as optional functions related to driverless operation (e.g. speed regulation), and to dispatching rules (Section 3.2). CBTC systems, tailor-made solutions, are successful in implementing many automation functionalities faster than ETCS for urban mass-transit applications in 
cities such as Vancouver, Canada and Beijing, China. Conversely, CBTC is manufacturer dependent, i.e. a detailed standard is not fully specified for suppliers to achieve an interoperable cross-frontier application [2]-[4].

In this paper, the authors analysed the reasons behind these differences, paying special attention to why CBTC has achieved driverless operation while ETCS outperforms CBTC regarding interoperability. To accomplish this, the authors first describe the separation distance principle used in each train control system, their terminology, and their main differences and challenges in terms of levels of implementation, radio communication systems, train integrity, and interoperability. Furthermore, this review gives insight into why CBTC and ETCS - despite what their names could indicate - should not be seen as being part of the same category, but rather two systems comprised of different functionalities.

\section{SEPARATION DISTANCE PRINCIPLES}

Before going into more detail, it is important to understand the two main separation distance principles used in railway operation, Fixed and Moving Block Operation, because they influence the type of infrastructure and software requirements needed. In Fixed Block Operation (also known as a conventional operation), the railway tracks are divided into block sections of around $1000 \mathrm{~m}$ and are often protected by lineside signals. In this type of operation, track circuits or axle counters are mounted on the tracks and indicate whether a block is free or not. Only one train is allowed to move in a block section at one time (Fig. 1). Examples of this type of operation are the ETCS Level 1 and Level 2, which are specified by the European Rail Traffic Management System (ERMTS) [5].

In contrast, Moving Block Operation (also known as absolute braking distance) works under the principle that the next danger point location, either the rear of the train ahead or movable track elements (e.g. switches), is known precisely. Under this principle, the minimum separation between trains is determined by the safe braking distance of the train plus an additional safety distance (Fig. 2). In other words, the separation distance between trains is not fixed, rather it changes continuously depending on the trains' speeds or movable infrastructure elements. Examples of this operation are ETCS Level 3, which has not yet been specified by ERTMS, and the CBTC, which has been specified to some extent by the Institute of Electrical and Electronics Engineers (IEEE) [3], [5], [6]. Moving Block Operation has the potential to increase the network capacity (i.e. more trains per hour) without major investment in the current infrastructure. However, its implementation could lead to large investments in train equipment, telecommunication infrastructure, and on-board equipment maintenance [7].

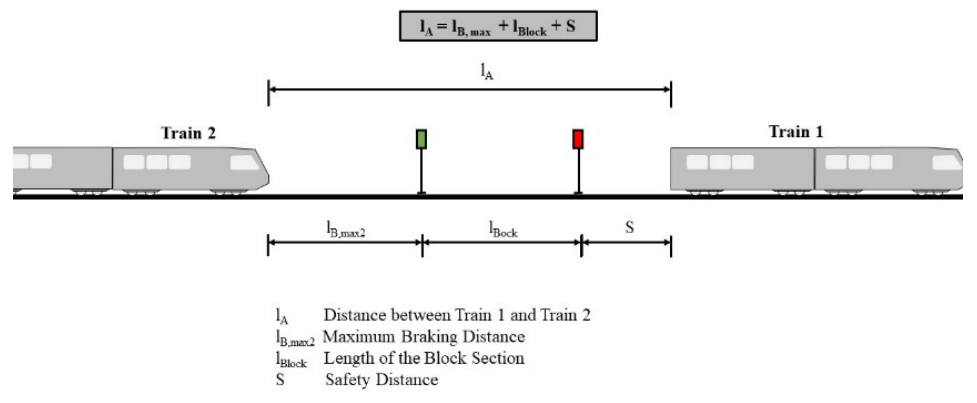

Figure 1: Fixed distance separation principle between consecutive trains - fixed block [5]. 


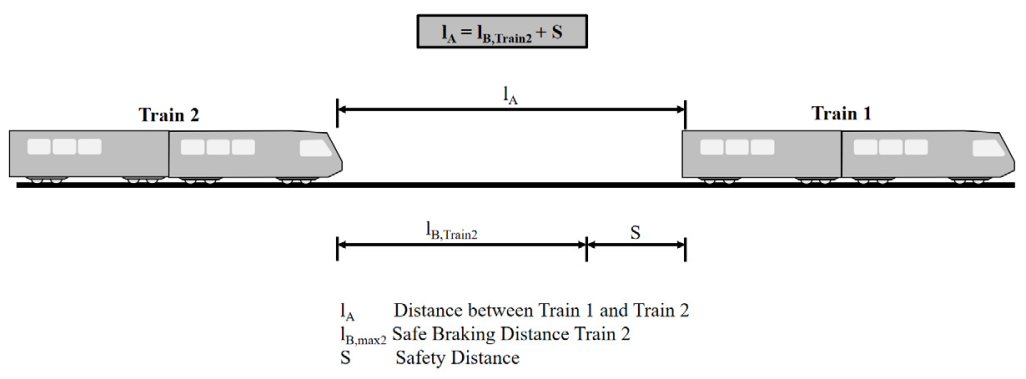

Figure 2: Absolute braking distance separation principle between consecutive trains - moving block [5].

\section{TRAIN CONTROL SYSTEM TERMINOLOGY}

\subsection{The myth of train control systems applications}

CBTC systems are mostly implemented in closed urban mass-transit systems because they require a higher line capacity (i.e. more trains per hour), shorter headways (i.e. the space or time interval between two successive trains), lower speed limits, and simpler and shorter networks (in contrast to heavy railway networks). On the other hand, ETCS is mostly implemented in heavy railway networks for the opposite reasons [3], [8]. Nevertheless, the trend of implementing a specific train control system for a specific railway network is slowly changing. For example, some countries plan to integrate ETCS Level 2 with additional Automatic Train Operation (ATO) functionalities into their suburban mass-transit railway networks (e.g. in Germany) [9]. Meanwhile, CBTC systems are been adopted in heavy passenger rail and heavy-haul applications (e.g. in Brazil) [10]. In addition, other initiatives combine both systems to integrate the heavy and light railway systems (e.g. in the UK) [11]. These deployments of CBTC and ETCS shatter the myth that each system is used specifically in just one type of railway network (heavy or light), proving that they can be adapted to different projects.

\subsection{Scope and functionalities}

Both CBTC and ETCS systems have acknowledged the definition of Grades of Automation (GoA) proposed by the International Association of Public Transport (UITP). The GoA (Table 1) is a classification - by functionalities and responsible - of the levels that make the automation of railway systems possible. The lowest level of automation is GoA1 where the driver performs all the main functionalities (setting train in motion, stopping the train, door closure, operation in event of a disruption), while in the highest level, GoA 4, the train control system regulates all the main functionalities. Nevertheless, independent of the driver's presence, the railway operator should assign a responsible person for the correct system functioning e.g. in the control centre.

CBTC and ETCS applications continuously use abbreviations to explain system functionalities. However, for each of these two control systems, the meaning of such abbreviations might vary. This could lead to misleading interpretations of their functionalities and scopes. Table 2 summarizes the perspectives of the main functionalities of train control systems for CBTC standards, ETCS standards, and for the UITP. The following paragraphs give a more detailed explanation of these perspectives. 
Table 1: Grades of automation and examples. (Source: Farooq and Soler [3], Pachl [5], and UITP [12].)

\begin{tabular}{|c|l|l|l|l|l|l|}
\hline $\begin{array}{c}\text { Grade of } \\
\text { Automa } \\
\text {-tion }\end{array}$ & $\begin{array}{c}\text { Type of } \\
\text { Train } \\
\text { operation }\end{array}$ & $\begin{array}{c}\text { Setting } \\
\text { Mrain in } \\
\text { Motion }\end{array}$ & $\begin{array}{c}\text { Stopping } \\
\text { Train }\end{array}$ & $\begin{array}{c}\text { Door } \\
\text { Closure }\end{array}$ & $\begin{array}{c}\text { Operation } \\
\text { in event of } \\
\text { Disruption }\end{array}$ & Examples \\
\hline GoA 1 & $\begin{array}{l}\text { ATP with } \\
\text { driver }\end{array}$ & Driver & Driver & Driver & Driver & ETCS Level 1 \\
\hline GoA 2 & $\begin{array}{l}\text { ATP and } \\
\text { ATO with } \\
\text { driver }\end{array}$ & Automatic & Automatic & Driver & Driver & $\begin{array}{l}\text { ETCS Level 2 } \\
\text { ETCS Level 3 }\end{array}$ \\
\hline GoA 3 & Driverless & Automatic & Automatic & $\begin{array}{l}\text { Train } \\
\text { attendant }\end{array}$ & $\begin{array}{l}\text { Train } \\
\text { attendant }\end{array}$ & $\begin{array}{l}\text { AnTC with } \\
\text { GoA 4 }\end{array}$ \\
$\begin{array}{l}\text { Train } \\
\text { Operation }\end{array}$ & Automatic & Automatic & Automatic & Automatic & $\begin{array}{l}\text { all } \\
\text { functionalities }\end{array}$ \\
\hline
\end{tabular}

Table 2: The perspectives of railway system functionalities by type of system.

\begin{tabular}{l}
\hline UITP \\
\hline OTC
\end{tabular}

System

For UITP, the Automatic Train Protection (ATP) has to ensure basic safety (e.g. avoiding collisions or exceeding speed limits) whereas the ATO assumes the functions of the driver except for door closing. UITP defines Automatic Train Control (ATC) as a general class of ATP that is in charge of route setting and train regulation [12].

CBTC standards additionally to the terms used by UITP describe the term Automatic Train Supervision (ATS) that monitors trains and adjusts their performance to maintain schedules. Regarding ATP and ATO functionalities, CBTC systems have similar meanings to UITP. CBTC Standard distinguishes ATP, ATO, and ATS as different subsystems inside of the ATC. The CTBC System must include ATP and may include ATO and/or ATS, but it needs to have the three functionalities to achieve full automation (GoA 4) [2].

Contrary to what one might think, ETCS as a Train Control System is closer related to the definition of ATP of CBTC Standards and UITP. Contrary to IEEE for CBTC, ERTMS does not contemplate the full automation of ETCS as an objective, ETCS is seen as a fail-safe 
component of signalling primarily independent of other optimization objectives (e.g. improve punctuality). Moreover, functionalities of CBTC, such as ATO and ATS are considered as external systems in ETCS but can be compatible with them e.g. ETCS over ATO is an alternative to integrate this functionality to the ETCS operation [9]. Similarly, the train dispatching operation (or ATS) is not a part of the ETCS specification. Initially, it was conceived by ERTMS as the European Train Management Layer (ETML), however, due to the complexity to integrate different management systems, its scope was limited to the development of an interface [13]. Currently, Shift2Rail, a European initiative made up of railway operators and manufacturers, develops an automated traffic management system interoperable with ETCS [14]. This Traffic Management System uses as inputs the rules and performance of fail-safe systems e.g. movement rules to reschedule trains more efficiently in case of delay. Moreover, we believe that if this Traffic Management System can coordinate both urban mass transit and heavy railway systems, independent of which train control system (ETCS or CBTC) is used, rescheduling of trains can be done more efficiently. That ultimately results in better use of resources, and hence a greater profit to end-users, railway operators, and infrastructure managers (e.g. reducing operational waiting time, operation costs, infrastructure optimization).

\section{DIFFERENCES AND CHALLENGES BETWEEN ETCS AND CBTC SYSTEMS}

\subsection{Evolution and levels}

In ETCS, the trains need to know three types of information: current position, the maximum allowed speed at a certain track section, and the message containing the next safe allowable position - called movement authority (MA). The rough current position is sent to the train via fixed Eurobalises mounted on the tracks, and between them, the train estimates on-board its fine position using different sensors (e.g. odometer). All ETCS levels use the same principle to estimate the current position; additionally, in ETCS Level 3 (not yet specified) satellite-supported systems are being considered for transmission of vital and non-vital information [15], although a question remains open regarding its suitability in adverse environments such as inside tunnels. For ETCS Level 2 and 3 thanks to the track-to-train bidirectional communication, trains also can transmit their position to the control centre (known as Radio Block Centre (RBC)). However, for the movement authority and maximum track allowable speed, the type transmission, and the logic behind it differ for each ETCS Level (Section 4.1).

For ETCS Level 1, the message of the movement authority and maximum track allowable speed for each block is transmitted from the lineside signals to the Lineside Electronic Unit (LEU), which sends the correct telegram to the controlled Eurobalises mounted on the tracks and finally from there to the train. If required, Euroloops or radio infill transmission could be integrated into the system to transfer the change of the lineside signal (e.g. from red to green) to the train early and avoid unnecessary braking of the train. In this level, track circuits or axle counters are required for the train integrity supervision (Fig. 3) [16]. In this level, an intermediate and affordable solution was conceived by ERTMS, called Limited Supervision. In this solution, the supervision of the driver following the braking curve is done only at the stop lineside signal and not along the tracks as it happens in the Level 1 Full Supervision (ETCS Level 1 LS).

For ETCS Level 2, instead of the lineside signals, LEU, and controlled Eurobalises, (which are optional), the vital information is transmitted by the RBC via Global System for Mobile Communications-Railway (GSM-R); and hence, a bidirectional continuous data 
transmission track-to-train can be achieved. The logic behind the movement authority estimation continues to be the Fixed Block Operation, and track circuits or axle clearance detection is also needed for train integrity supervision (Fig. 4) [16], [17].

For ETCS Level 3, the vital information is transmitted through radio communication. The logic behind the movement authority in this level is the Moving Block Operation [16], [18]. The latter means that the trains can travel closer to each other and the infrastructure can be optimized. For the real Moving Block Operation, track circuits or axle clearance detection is not needed for train integrity. So far, the most critical issues to complete the specifications of Level 3 are the definition of the radio communication technology (Section 4.2), and the assurance of the continuous supervision of train integrity (Section 4.3) (Fig. 5) [6], [16].

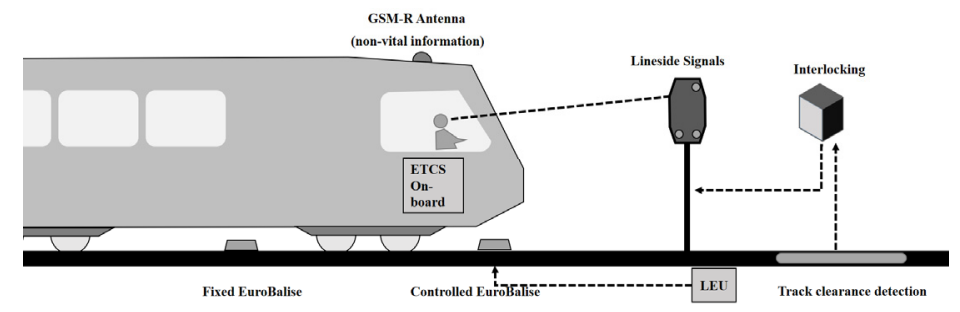

Figure 3: Equipment for ETCS - level 1 [16].

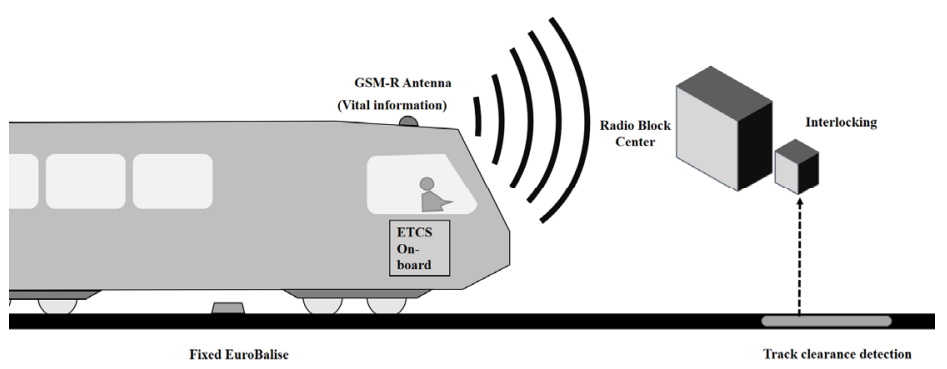

* optional: lineside signals, LEU, and controlled Eurobalises

Figure 4: Equipment for ETCS - level 2 [16].

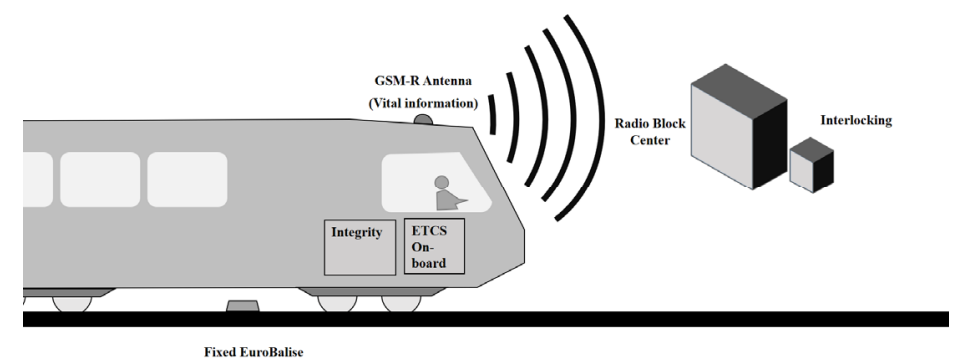

Figure 5: Equipment for ETCS - level 3 [16]. 
ETCS Level 3 is comprised of four different variants: overlay, hybrid, virtual, and moving block. Overlay variant integrates ETCS Level 1 or Level 2 systems plus the hybrid solution or plus the virtual block variants. The hybrid variant uses a limited amount of trackside circuits to guarantee train integrity detection in case of radio communication centre shut down. The virtual block solution uses virtual blocks, defined by the software and database, for managing track occupancy and train separation. Fig. 6 shows an example of the hybrid solution using virtual block sections. Trains report their position to the radio control centre, and it assigns them to each virtual block. In this variant, track circuits are not needed. To achieve the hybrid and virtual block solutions, only software and database updates are required. True moving block variant (Section 2) calculates the moving authority based on real-time train speed and position, and the state of other infrastructure elements; track circuits are not needed. Therefore, block size changes with the train speed, thus increasing network capacity [6]. Although, the overall capacity is restricted not only by the headway between trains, but also by the infrastructure itself (e.g. time to set up switches), and most significantly by the passenger boarding and alighting time at the station.

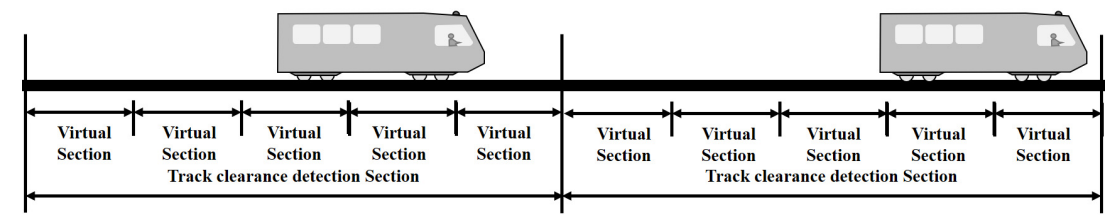

Figure 6: ETCS level 3 variant - hybrid with virtual block [6].

There are differing opinions about whether to build a new system or to migrate legacy systems to either ETCS Level 2 or Level 3. Theoretical studies have demonstrated that the headway for high-speed lines can be improved compared with ETCS Level 1 from 14\% to 52\% using ETCS Level 2, and up to 62\% using ETCS Level 3 [16], [19], [20]. However, a particular case in Level 2 can be achieved by splitting the network into very small sections, smaller than the safety distance required for Moving Block discussed in Section 2 (Fig. 2). In this case, the network capacity with ETCS Level 2 might similar to ETCS Level 3. Some argue that because ETCS Level 2 does not need lineside signals, and technically, it could achieve a similar capacity performance as ETCS Level 3 (i.e. Hybrid ETCS Level 3), this solution could be a more profitable option. While others argue that ETCS Level 2 still needs track circuits or axle counters for integrity detection, and each additional piece of equipment requires extra and costly wayside hardware and maintenance. Either way, the investment of each level might be also dependent on the transition cost to the future railway communication technology (Section 4.2) [3].

CBTC systems have had their own evolution before becoming what they are today. Morar outlines four generations of train control systems, in which CBTC Systems is the fourth generation. Here, track circuits or axle counters are no longer needed, trains move according to Moving Block or Virtual Block principles, and the logic of estimating the moving authority depends on the train-borne, and the bidirectional and continuous train-to-wayside communication [4].

CBTC systems components include (Fig. 7): (1) integrated networks: comprised of train on-board network, train-to-trackside radio network, trackside backbone network; (2) wayside components: Zone Controller (ZC), Computer-based Interlocking (CI), and Access Points 
(AP); and (3) on-board components: comprise Vehicle on-board controller-computer (VOBC), on-board ATP and ATO, Radio Communication System (RCS) [3]. CBTC systems estimate trains rough position through beacons installed on the tracks, and fine position through sensors installed on-board. AP serve specific Wi-Fi cells along the track. Because Wi-Fi has short-range coverage, AP are placed close to each other, such that their coverage areas overlap. ZC estimates the movement authority, and sends it via Wi-Fi to each AP, and finally, from there to each train (Section 4.2) [2], [3].

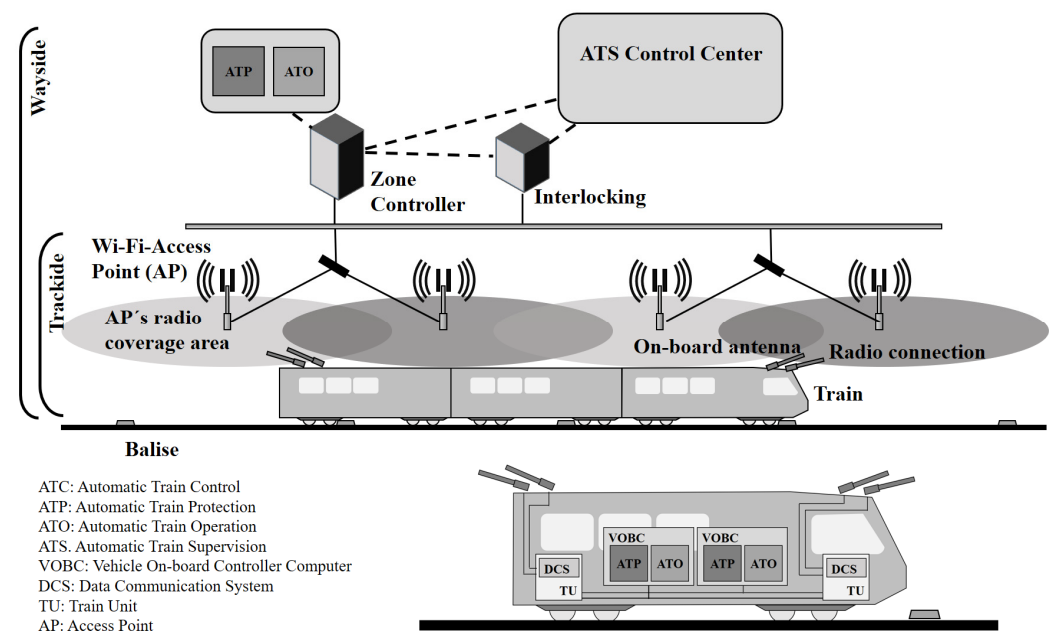

Figure 7: Equipment for CBTC systems [3].

Furthermore, CBTC is characterized by the spatial, frequency, temporal and power redundancy e.g. redundant AP coverage; as well as its remote diagnostic features that ensure its high availability. CBTC systems perform: (1) Service Affecting Diagnosis e.g. perform periodic self-testing of radio hardware, (2) Corrective Maintenance Diagnostics e.g. define the reasons of radio communication failure, and (3) Predictive Maintenance Diagnostics e.g. predict radio communication failure before it happens [21].

\subsection{Radio communication}

In CBTC systems, the train-to-trackside radio network is mostly Wi-Fi. Despite its susceptibility to high adjacent-channel interferences, network congestion, and its short-range capabilities at a high-frequency band, Wi-Fi radio communication in the $2,4 \mathrm{GHz}$ and $5 \mathrm{GHz}$ frequencies ranges is highly popular, because: (1) its unlicensed frequency band, (2) its high availability of cost-effective radio equipment, (3) ease of installation for indoor application, and (4) external-authority independent operation. In some cases, the Global Navigation Satellite System (GNSS), e.g. Global Positioning System (GPS) may work as a supplementary system of CBTC systems [3]. For heavy railway applications and outdoor applications, Wi-Fi radio communication is not seen as a viable solution due to its high latency. Heavy railway operations require low latencies and high reliability e.g. for virtual coupling [22].

For ETCS applications, the GSM-R is applied as the standard of radio communication technology since 1994. In Level 1, it might be used only for voice communication. In Level 
2, for train-to-track communication of both voice and vital communication. In Level 3, it is no longer clear if GSM-R will be used, because GSM-R is expected to become financially unsustainable to maintain due to obsolescence of the underlying $2 \mathrm{G}$ mobile technology and increase of all future needs. The International Union of Railways (UIC) launched the Future Railway Mobile Communication System (FRMCS) project in 2012 to specify the user requirements of the new radio communication technology for heavy and light railway systems [23]. The fast evolution of the telecommunication sector (like the earlier launch of $5 \mathrm{G}$ for the mobile network market) has increased the complexity of FRMCS specification, and some previous efforts (i.e. LTE-R specification) were lost. Even though FRMCS technology is not clear yet, it is more likely to be $5 \mathrm{G}$. It is a promising alternative that is being researched, although not yet implemented.

\subsection{Train integrity}

Train integrity refers to the system's ability to detect the train completeness with respect to its length at all times (i.e. to confirm the train has not lost any wagons), even when if the radio communication stops working. The importance of detecting integrity lies in the safe operation of the whole system, as well as avoiding reducing the network capacity due to the sudden stop of trains [6]. In CBTC systems, this is achieved through a periodic self-testing of radio hardware. Continuous messages of train completeness are sent from the antennas in the rear and head of the train to the wayside infrastructure by radio when the message is not sent the degraded mode (or failure mode) is activated. Under this mode, CBTC systems operate in a safe manner and minimize the operational impact by either using auxiliary wayside systems and/or strict operating rules. In ETCS Level 3 is not yet clear how to implement this principle. Specifically, for freight transport, the number and diverse wagons typologies make it harder and expensive to equip all of them with this technology. For this reason, hybrid ETCS Level 3, which still uses some track detection devices to guarantee train integrity, is seen by the industry and research groups as the most suitable option to support ETCS Level 3 in freight transport [3]. A second initiative, suitable for passenger and freight trains equipped with ETCS Level 3, it is to mount at each end of each wagon a Coupler Monitor Device (CMD). These devices report train integrity to the Head End Device (HED), located at the front of the train, and it, in turn, reports to the RBC [24]. These initiatives are still under development and are not yet included in the specification of ETCS Level 3.

\subsection{Interoperability and interchangeability}

Interoperability is the ability to operate a train equipped with an on-board system provided by one supplier on lines with wayside equipment provided by another supplier. Interchangeability is the ability to exchange elements of the systems with components provided by a supplier different from the original supplier [4]. Interoperability and interchangeability transcend beyond allowing the operation across-frontiers, but they are key factors in keeping system prices low for both heavy and light railway systems worldwide. Railway operators are not bound to one supplier during the system life cycle, and benefit from future developments of different suppliers (e.g. hardware and software updates). In this respect, IEEE needs to work more to describe the CBTC systems standards precisely, such that more suppliers could adhere to them [3]; meanwhile, ETCS has successfully achieved this for Level 1 and 2.

Regarding interoperability, the project Next Generation Train Control Systems (NGTC) carried out a detailed analysis of CBTC and ETCS functionalities, and identified common 
core and domain-specific functions for light and heavy railway applications. The aim of the project is to design the specifications of the future train control systems (the evolution of ETCS ) with higher compatibility to CBTC systems. NGTC concentrates on the common core functions between ETCS and CBTC systems that correspond principally to the ATP functions [25]. The first step in identifying commonalities between systems has been accomplished, but it is necessary to take this initiative a step further, design and implement the specification compatible with both systems.

Table 3 summarizes the characteristics of CBTC and ETCS regarding the different characteristics explained above.

Table 3: ETCS and CBTC comparison. (Source: Farooq and Soler [3], and Stanley [16].)

\begin{tabular}{|c|c|c|c|c|}
\hline Level & Level 1 & Level 2 & Level 3 & CBTC \\
\hline Application & (mostly)Heavy & (mostly)Heavy & (mostly)Heavy & (mostly)Light \\
\hline Operation & Fixed Block & Fixed Block & Moving Block & Moving Block \\
\hline Lineside Signals & Yes & Not needed & Not needed* & Not needed* \\
\hline $\begin{array}{l}\text { Interoperable and } \\
\text { Interchangeability }\end{array}$ & Yes & Yes & Yes & No \\
\hline Functionalities & ATP & $\begin{array}{l}\text { ATP } \\
\text { compatible with } \\
\text { ATO }\end{array}$ & $\begin{array}{l}\text { ATP } \\
\text { compatible } \\
\text { with ATO } \\
\end{array}$ & $\begin{array}{l}\text { ATP, ATO, } \\
\text { ATS, Diagnosis }\end{array}$ \\
\hline Standards by & ERTMS & ERTMS & $\begin{array}{l}\text { Not yet } \\
\text { specified }\end{array}$ & $\begin{array}{l}\text { Partially by } \\
\text { IEEE }\end{array}$ \\
\hline Route Interlocking & Yes & Yes & $\begin{array}{l}\text { Not yet } \\
\text { specified }\end{array}$ & Yes \\
\hline $\begin{array}{l}\text { Type Data } \\
\text { Transmission }\end{array}$ & $\begin{array}{l}\text { Spot } \\
\text { (Semicontinuous), } \\
\text { Unidirectional } \\
\text { (from track to } \\
\text { train) }\end{array}$ & $\begin{array}{l}\text { Continuous } \\
\text { Bidirectional } \\
\text { Track-to-train }\end{array}$ & $\begin{array}{l}\text { Continuous } \\
\text { Bidirectional } \\
\text { Track-to-train }\end{array}$ & $\begin{array}{l}\text { Continuous } \\
\text { Bidirectional } \\
\text { Track-to-train }\end{array}$ \\
\hline $\begin{array}{l}\text { Vital information } \\
\text { is transmitted } \\
\text { through }\end{array}$ & $\begin{array}{l}\text { Lineside signals, } \\
\text { and Electronic } \\
\text { Unit, controlled } \\
\text { Eurobalises } \\
\text { (Euro loops and } \\
\text { Radio Infill) }\end{array}$ & $\begin{array}{l}\text { Radio } \\
\text { communication } \\
\text { via GSM-R }\end{array}$ & $\begin{array}{l}\text { Radio } \\
\text { communication } \\
\text { (To be defined, } \\
\text { probably } 5 \mathrm{G} \text { ) }\end{array}$ & $\begin{array}{l}\text { Radio } \\
\text { communication } \\
\text { via WiFi }\end{array}$ \\
\hline $\begin{array}{l}\text { Track clearance } \\
\text { detection }\end{array}$ & $\begin{array}{l}\text { Track circuits/ } \\
\text { axle counter }\end{array}$ & $\begin{array}{l}\text { Track circuits/ } \\
\text { axle counter }\end{array}$ & $\begin{array}{l}\text { On board (To } \\
\text { be defined) }\end{array}$ & $\begin{array}{l}\text { Continuous } \\
\text { message }\end{array}$ \\
\hline
\end{tabular}

* In case of system failure, wayside signals might be required.

\section{CONCLUSION}

In this paper, the terminology, differences, and challenges of the CBTC and ETCS were discussed. One of the most important - and usually overlooked - differences between them is associated with their scope. ETCS is conceived as a standardized, fail-safe system for train operation, whereas CBTC systems are not fully specified and have more integrated functionalities that allow full automation such as driverless functionalities related to ATO, and train rescheduling related to ATS, to keep punctuality. ETCS does not aim to fully obtain automated operation, and ATO and ATS functionalities are not part of the scope of ETCS. However, those functionalities are developed separately as external systems compatible with ETCS for heavy and light railway applications (e.g. Traffic Management Systems). Nevertheless, the question remains if it is reasonable to integrate these functionalities, 
considering the fact that they are interdependent. For example, the outputs of safe operation (e.g. movement authority) are inputs of the Traffic Management System. By doing that, better service for railway users and lower operating costs for railway operators and infrastructure managers could be achieved.

Additionally, CBTC systems work under the moving block principle using mostly a continuous train-to-track radio communication via $\mathrm{Wi}-\mathrm{Fi}$, while ETCS could use either Fixed Block or Moving Block Operation. Fixed Block Operation has already been specified for ETCS Level 1, which combines lineside signals, controlled Eurobalises and track circuits or axle counters for a spot track-to-train communication, and Level 2 which combines GSM-R radio communication, and track circuits or axle counters to perform a continuous train-to-track communication. The Moving Block Operation is expected to be included in ETCS Level 3 specification that is under development. The success of the ETCS Level 3 specification process is highly dependent on the definition of the next radio communication for railway applications and how to achieve train integrity.

Regarding the advantages, CBTC was able to achieve a higher degree of automation, implement several functions including several types of self-diagnosis, and apply the Moving Block Operation faster than ETCS. Indeed, the radio communication technology used for CBTC systems (Wi-Fi) might not be optimal for heavy railway applications; its fast evolution can help as a lesson learned for ETCS Level 3; for example, to identify key factors during the planning phase that guarantee a smooth train-to-track communication in complex environments. Similarly, the ERMTS could learn from the good practices regarding moving block logic and train integrity already implemented in CBTC systems to specify ETCS Level 3. Finally, CBTC systems could learn from ETCS regarding interoperability and interchangeability. ERMTS has already accomplished these features for ETCS Level 1 and 2, and it is working towards the same goal for the specification of ETCS Level 3.

\section{ACKNOWLEDGEMENTS}

We gratefully acknowledge Maureen Kösters, Aditi Kumawat, Ijeoma Osakwe for the valued suggestions regarding this paper.

\section{REFERENCES}

[1] European Rail Traffic Management System, ERTMS Deployment Statistics. http://www.ertms.net/?page_id=58. Accessed on: 18 Jan. 2020.

[2] IEEE Standard for Communications-Based Train Control (CBTC) Performance and Functional Requirements, IEEE: Piscataway, 1999.

[3] Farooq, J. \& Soler, J., Radio communication for communications-based train control (CBTC): A tutorial and survey. IEEE Communications Surveys and Tutorials, 19, pp. 1377-1402, 2017.

[4] Morar, S., Evolution of communication based train control worldwide. IET Professional Development Course on Railway Signalling and Control Systems (RSCS 2012) Proceedings, London, UK, 2012.

[5] Pachl, J., Systemtechnik des Schienenverkehrs, Springer Fachmedien Wiesbaden: Wiesbaden, 2018.

[6] Furness, N. et al., ERTMS Level 3-The Game Changer, IRSE NEWS: 2-9.

[7] Schneider, L., Zugbeeinflussungssysteme für Stadtbahnen im Vergleich. Der Eisenbahn Ingenieur (EI), pp. 31-34, 2019.

[8] Hansen, I.A., Pachl, J. \& Albrecht, T., Railway Timetabling \& Operations: Analysis, Modelling, Optimisation, Simulation, Performance Evaluation, 2nd ed., Eurailpress: Hamburg, 2014. 
[9] Untersuchung zur Einführung von ETCS im Kernnetz der S-Bahn Stuttgart: Abschlussbericht (17FEI27440), January 2019.

[10] Vieira, P. et al., Deploying a CBTC System in a Heavy-Haul Railroad, 2008.

[11] Arpaci, M.E., Case Study: Coexistence of CBTC and ETCS on Crossrail Project in London, 2016.

[12] UITP, Press Kit Metro Automation Facts, Figures and Trends, Belgium.

[13] UIC, ERTMS: International Union of Railways. https://uic.org/rail-system/ertms/.

[14] Shift2Rail, Innovation Programme 2. https://shift2rail.org/research-development/keydocuments/. Accessed on: 4 Feb. 2020.

[15] Zweigel, R., Gehrt, J.-J. \& Abel, D., Scientific Railway Signalling Symposium 2018, Darmstadt, Germany, 2018.

[16] Stanley, P., ETCS for Engineers, DVV Media Group Eurail Press: Hamburg, 2011.

[17] Railway Signalling. The ERTMS/ETCS signalling system, 2013-2014.

[18] Damy, S., A novel GNSS-based positioning system to support railway operations, Doctoral thesis, Imperial College London, 2017.

[19] VÄYLÄ. ERTMS/ETCS Level 2 Capacity Benefits on the City Lines of the Helsinki Region, 2019.

[20] Winter, P., Compendium on ERTMS, European Rail Traffic Management System, DVV Media Group Eurailpress: Hamburg, 2009.

[21] Ali, N., 7 Key CBTC Functions Transit Operator Must Understand, CBTC Solutions, 2017.

[22] Briso-Rodríguez, C., García-Loygorri, J.M. \& Zhang, L., Transmission-based signaling systems. Modern Railway Engineering, ed. A. Hessami, InTech: Rijeka, 2018.

[23] SYSTRA, Study on the architecture of on-board radio communication, 2018.

[24] Martin, U., Körner, M. \& Beck, R., Funktionale Sicherheitsanforderungen an eine ETCS L3 kompatible Mittelpufferkupplung. Eurail, 107, pp. 15-19, 2015.

[25] Gurník, P., Next generation train control (NGTC): More effective railways through the convergence of main-line and urban train control systems. Transportation Research Procedia, 14, pp. 1855-1864, 2016. 